\title{
STRUGGLE FOR THE RIGHT OR CONFLICT OF LAW ASPECTS OF LEGITIMATE INTERESTS OF THE TAXPAYER
}

\author{
Sergei A. Yadrikhinsky \\ North-Western Institute (Branch) of Kutafin Moscow State Law University (MSLA), \\ Vologda, Russian Federation
}

\begin{abstract}
Introduction: the concept of legitimate interests of the taxpayer, despite its lack of research, has both theoretical and applied significance. At the same time, not only has the science of financial law not developed a clear understanding of the legal nature of this phenomenon, but also there is almost no research related to the process of its implementation, overcoming the legal obstacles, solving the conflict of laws issues. The purpose of the study is to consider a relatively new concept of "conflict of law interests of the taxpayer" as an object of scientific research and evaluation; to analyze the legitimization process of the actual interest: to transform it into a legitimate one. Methods: the methodological framework for the study is a set of various general and special methods of knowledge of the phenomena of legal reality. Among them the legal-dogmatic and historical-legal methods are particularly important. Results: the possibility of use in the scientific revolution of the concept of "conflicting legitimate interests of the taxpayer" is proved; its perfect and functional aspects are shown. The conflict status of the actual interest does not mean that it cannot be legally exercised in the future. The realization of a conflict of laws interest is not a straightforward process because of its ambivalent nature. For its implementation, the special conditions are necessary to expand the boundaries of what is permitted, to reconcile the claims of the taxpayer with the legal environment of their location. This depends on the level of development of society and the state in general, and the democratization of tax law in particular. Conclusions: on the basis of the synthesis of two constructs of "law" and "interest" it is concluded on the possibility to implement even those aspirations of the taxpayer, which initially did not find their support in court and (or) in the tax authority.
\end{abstract}

Key words: legal interest, subjective right, taxpayer, tax authority, permission, claim; conflict of interest, transformation of interest.

Citation. Yadrikhinsky S.A. Struggle for the Right or Conflict of Law Aspects of Legitimate Interests of the Taxpayer. Legal Concept, 2019, vol. 18, no. 3, pp. 68-75. (in Russian). DOI: https://doi.org/10.15688/lc.jvolsu.2019.3.10

УДК 336.2

ББК: 67.402
Дата поступления статьи: 30.05.2019

Дата принятия статьи: 20.06.2019

\section{БОРЬБА ЗА ПРАВО, ИЛИ КОЛЛИЗИОННЫЕ АСПЕКТЫ ЗАКОННЫХ ИНТЕРЕСОВ НАЛОГОПЛАТЕЛЬЩИКА}

\author{
Сергей Александрович Ядрихинский \\ Северо-Западный институг (филиал) Университета им. О.Е. Кутафина (МГЮА), \\ г. Вологда, Российская Федерация
}


методы. Результаты: обосновывается возможность использования в научном обороте понятия «коллизионные законные интересы налогоплательщика», показаны его идеальная и функциональная стороны. Коллизионный статус фактического интереса не означает юридическую невозможность его осуществления в будущем. Реализация коллизионного интереса не является прямолинейным процессом в силу своего амбивалентного характера. Для его воплощения в жизнь необходимы специальные условия, расширяющие границы дозволенного, согласующие притязания налогоплательщика с правовой средой их нахождения. Это зависит как от уровня развития общества и государства в целом, так и от демократизации налогового права в частности. Выводы: на основе синтеза двух конструктов «права» и «интерес» делается вывод о возможности претворения в жизнь даже тех стремлений налогоплательщика, которые изначально не нашли своей поддержки в суде и (или) в налоговом органе.

Ключевые слова: законный интерес, субъективное право, налогоплательщик, налоговый орган, дозволение, притязание, коллизия, преобразование интереса.

Цитирование. Ядрихинский С. А. Борьба за право, или Коллизионные аспекты законных интересов налогоплательщика // Legal Concept = Правовая парадигма. - 2019. - T. 18, № 3. - C. 68-75. - DOI: https:// doi.org/10.15688/lc.jvolsu.2019.3.10

\section{Введение}

Теория законных интересов в зависимости от соответствия нормативным предписаниям и (или) сложившейся правоприменительной практике позволяет классифицировать интересы налогоплательщика на неколлизионные и коллизионные. Первые в полной мере соответствуют действующему законодательству о налогах и сборах, эти притязания признаются правоприменительными органами (налоговыми органами, судом) и не встречают каких-либо преград на пути своего осуществления. Законность этих интересов не подвергается сомнению.

Те же интересы налогоплательщика, которые правоприменитель либо законодатель не поддерживают, то есть не наделяют качеством «законных», попадают в разряд коллизионных. Понятие «коллизия» происходит от лат. collisio - «столкновение» и в правовом смысле понимается как столкновение противоположных сил, стремлений, интересов, взглядов [7, с. 283].

В основе коллизионных законных интересов лежит допущение нетождественности права и юридической нормы, права и закона. Оно опирается на исторический опыт человечества, когда закон, отражающий интересы только одного класса или узкой группы лиц, находящихся у власти, выступал средством вплетения в нормативную ткань абсолютно произвольных положений, не имеющих ничего общего с правом. Очевидно, не все законы всегда являются адекватным выразителем права как формы всеобщей справедливости.
Соответственно, из всей совокупности законов или отдельных нормативных положений какая-то их доля может относиться к неправовым. Подтверждением этому является практика органа конституционного контроля, признающая время от времени отдельные юридические нормы не соответствующими Конституции РФ. По верному замечанию судьи Конституционного Суда РФ Г.А. Жилина, «противоречащий праву закон $<$...> находится в прямом противоречии с его правоохранительной функцией» $[4$, с. 8$]$.

Опираясь на различие права и закона, можно выделить ту часть стремлений налогоплательщика, которая по своей сути соответствует требованиям права как всеобщего выразителя общечеловеческих идеалов и ценностей, мерила справедливости, но во временном континууме не отвечает нормативным положениям действующего закона. Либо сложившаяся правоприменительная практика исходит из иного понимания закона. Законными эти интересы представляются только в сознании их обладателя. Правовая среда или пространство, в котором они находятся, отторгают данные стремления налогоплательщика. Таким образом, юридический базис, позволяющий говорить о коллизионных законных интересах как правовом явлении, состоит в широком понимании права, которое может не совпадать в своем объеме с действующими юридическими нормами. В этой парадигме понятие «законность» должно уступить место понятию «правозаконность». Именно «в условиях режима правозаконности, - по верному замечанию К.И. Амирбекова, - человек 


\section{ТЕОРИЯ И ПРАКТИКА ГОСУДАРСТВЕННО-ПРАВОВОГО РАЗВИТИЯ}

может вступить “в спор о праве” с самим законодателем, если действующее позитивное право, выраженное в законодательстве, не отражает идею ценности прав человека» [1].

\section{Что же дает надежду на преобразование коллизионного интереса в законный?}

Граница между «коллизионным» и «законным» интересом подвижна и не является абсолютной. Очень часто она обусловлена субъективным критерием (мнением компетентного органа), поскольку правообразование и правоприменение - это продукты сознательно-волевой деятельности людей, что делает ее зыбкой, неустойчивой.

Если же носитель коллизионного интереса стремится к признанию его законным, иначе - к справедливости, то он в иеринговском духе обречен на борьбу за эту справедливость, за свой интерес. В основе данной борьбы лежит концептуальная идея о несоответствии субъективных представлений законодателя или правоприменителя о предмете интереса объективному положению вещей или праву. Подобные ошибки (заблуждения) являются результатом неверного, искаженного отражения действительности.

Дело в том, что все предметы, процессы, явления всегда многосторонни, нет предметов, у которых только одна сторона. Сами предметы не обнаруживают себя перед людьми такими, какие они есть. Перед человеком предстают всегда только определенные стороны или свойства предметов или событий. Люди обычно предпочитают замечать и акцентировать внимание на той стороне события, которая им выгодна, признание которой приносит им пользу. Все это в практической деятельности приводит к расхождению субъективного знания о предмете с подлинной его сущностью. Очевидно, односторонние представления о чем-либо нельзя признать истинными, правильными, соответствующими реальной действительности. Одностороннее знание о правовом объекте неполно и относительно, поэтому нередко то, что сегодня нам кажется очевидным, на деле оказывается заблуждением, и наоборот: то, что еще вчера казалось нам невозможным, уже завтра может превратиться в реальность.
Такое противоречивое развитие права отнюдь не дискредитирует его. Напротив, только преодолев противоречия, право самоорганизуясь наделяется свойствами легитимности (от лат. legitimus «согласный с законами, законный, правомерный»), реципроктности (от лат. reciprocus «взаимный, взаимодействие») и когерентности (от лат. cohaerens «находящийся в связи», имеется в виду логическая связанность и непротиворечивость).

Как справедливо отмечал А.М. Ларин, «никому не запрещено быть завтра умнее, чем сегодня. Если придет осознание ошибки, найдется и способ ее исправления» [5, с. 54].

\section{Содержание коллизионных интересов}

Проблема коллизионных интересов тесно связана с вопросом об их значимости для общества и государства в конкретный момент времени. На наш взгляд, в содержании коллизионных интересов следует выделить их идеальную сторону (идея права или правовое основание) и функииональную сторону в контексте текущих, действующих налоговых отношений.

Первая сторона выражается в представлениях о праве как неком идеальном мериле справедливости, или, иначе, содержит ответ на вопрос, почему притязание налогоплательщика подлежит удовлетворению.

Вторая сторона касается его предназначения, иначе - представления о том, как данный интерес может повлиять на сложившиеся налоговые отношения, какую нагрузку он несет для общества, государства, бюджета и т. д. Здесь содержится вопрос, насколько он необходим в данный момент времени, созданы ли для него условия, вписывается ли он сам в действующую правовую систему.

Интерес может быть правовым, но преждевременным. Вполне возможно, что для его реального воплощения время просто не подошло.

Скажем, с позиции сегодняшнего дня рабство является преступным явлением настолько безусловным и очевидным, что ни одному здравомыслящему человеку не придет в голову идея утверждать обратное. Если бы это своим современникам заявил прогрес- 
сивный мыслитель Аристотель, являющийся убежденным защитником прав человека, частной собственности и моногамной семьи, один из основоположников концепции справедливости (актуальной и по сей день), то вряд ли он нашел бы у них понимание. Рабство у Аристотеля этически оправданно, оно, по мысли философа, общественно необходимо. «Одни люди по природе свободны, другие рабы, и этим последним быть рабами и полезно и справедливо» [2, с. 15]. Аристотель рабовладельческий строй считал вполне естественным и справедливым.

Исходя из того, что право подвижно, спустя определенное время объективно может возникнуть и иная оценка интереса налогоплательщика.

\section{Генезис коллизионного интереса} налогоплательщика в судебной практике

Рассмотрим генезис интереса налогоплательщика в получении справки по лицевому счету налогоплательщика, отражающей реальное состояние расчетов с бюджетом для ситуаций, в которых у налогоплательщика числится задолженность по налогам, сборам, пеням и штрафам, но в силу причин юридического характера ее невозможно взыскать.

Согласно подп. 10 п.1 ст. 32 НК РФ [6] запрашиваемая справка готовится лишь на основании данных информационных ресурсов налогового органа.

Таким образом, налоговый орган на протяжении длительного периода времени может предоставлять сведения о числящейся за налогоплательщиком задолженности по налогам, сборам, пеням и штрафам, невзирая на невозможность ее взыскания, что, в свою очередь, будет порождать конфликтную ситуацию.

Предоставление справки по лицевому счету налогоплательщика в таком виде создает существенные препятствия для осуществления им предпринимательской деятельности и не может не затрагивать законные интересы налогоплательщика в плане получения объективной и полной информации, отражающей реальное состояние расчетов с бюджетом. Данная справка (точнее сведения в ней) очевидно обладает определенной ценностью для налогоплательщика, поскольку отсутствие задол- женности характеризует налогоплательщика как лицо добросовестное, финансово устойчивое, успешное и т. д., и наоборот: наличие задолженности говорит об обратном и может иметь для него негативные последствия. Вышеуказанная справка может являться проводником к достижению налогоплательщиком желаемых благ в сфере предпринимательской и иной экономической деятельности. Стремление получить ее продиктовано тем, что данный документ способствует, в частности, привлечению кредита [12], получению лицензии на осуществление определенного вида деятельности [14], участию в конкурсе на размещение государственного заказа [15], реорганизации компании налогоплательщика и т. д.

Утрата налоговым органом возможности принудительного взыскания сумм налогов, пеней, штрафа, то есть непринятие им в установленные сроки надлежащих мер к взысканию, сама по себе не является основанием для прекращения обязанности налогоплательщика по их уплате и, следовательно, для исключения соответствующих записей из его лицевого счета.

Вместе с тем интерес в неуплате такого налога приобретет качество законного, несмотря на то, что сам закон (ст. 44 НК РФ) не предусматривает такого основания прекращение налоговой обязанности. В основе данного интереса лежит посыл об утрате налоговым органом возможности принудительного взыскания данного налога и, соответственно, пеней, штрафов.

Один из виднейших ученых в области финансового права, французский политологфинансист П.-М. Годме справедливо отмечал, что «налогоплательщик только потому платит налог, что знает о существовании принудительных мер, и в случае отказа платить такие меры будут приняты и его заставят заплатить с излишком» [3, с. 371]. Этот же ученый указывал, что «элемент принуждения настолько важен в понятии налога, что это влечет за собой исключение из налоговой сферы поступлений, не носящих принудительный характер» [3, c. 373].

Исключение соответствующих записей из лицевого счета налогоплательщика возможно только на основании судебного акта, в соответствии с которым налоговый орган 


\section{ТЕОРИЯ И ПРАКТИКА ГОСУДАРСТВЕННО-ПРАВОВОГО РАЗВИТИЯ}

утрачивает возможность взыскания недоимки, пеней, штрафов в связи с истечением установленного срока их взыскания, в том числе в случае отказа в восстановлении пропущенного срока подачи в суд заявления о взыскании этих сумм (подп. 5 п. 3 ст. 44 и подп. 4 п. 1 ст. 59 НК РФ).

Пленум ВАС РФ в Постановлении от 30.07.2013 № 57 «О некоторых вопросах, возникающих при применении арбитражными судами части первой Налогового кодекса Российской Федерации» [11] аналогично разъяснил, как налогоплательщик может защитить свой интерес: путем подачи в суд заявления о признании сумм, возможность принудительного взыскания которых утрачена, безнадежными ко взысканию и обязанности по их уплате прекращенной.

В дальнейшем Конституционный Суд РФ в Определении от 26.05.2016 № 1150-О [8] разъяснил, что подп. 4 п. 1 ст. 59 НК РФ не содержит каких-либо непреодолимых препятствий в реализации возможности признания сумм налога, пени и штрафа безнадежными к взысканию - по инициативе как налогового органа, так и налогоплательщика.

Однако путь к такому итоговому результату оказался достаточно долгим и тернистым.

В 2005 г. Президиум ВАС РФ, отменяя судебные акты нижестоящих судов в части понуждения налоговой инспекции исключить из лицевого счета налогоплательщика суммы недоимки и задолженности по пеням, безнадежные к взысканию (последняя утратила право на их взыскание как во внесудебном, так и в судебном порядке), указал, что наличие в карточке лицевого счета сведений о суммах недоимки и задолженности по пеням и штрафам, сроки взыскания которых пропущены, не нарушает прав и законных интересов налогоплательщика [13].

То есть аргументы налогоплательщика о значительном снижении возможности по участию в конкурсах, тендерах, в получении кредитов и т. д. не являлись достаточно убедительными для суда.

В 2009 г. тот же Президиум ВАС РФ отказался от своей же позиции. Суд пришел к диаметрально противоположному выводу: в справке необходимо отражать объективную информацию, поэтому наряду со сведениями о задолженности налогоплательщика в документе должно быть указано, что инспекция утратила право на ее взыскание. Президиум ВАС РФ особо отметил, что неполная информация о задолженности по налогам, сборам, пеням и штрафам, числящейся за налогоплательщиком, затрагивает его право на достоверную информацию, необходимую ему для осуществления своих прав и законных интересов, в том числе в предпринимательской и (или) иной экономической деятельности [12].

В 2013 г. Пленум ВАС РФ уже категорично указал на обязанность налогового органа немедленно исключать из лицевого счета налогоплательщика записи о задолженности, безнадежной ко взысканию, после вступления в силу судебного акта по любому налоговому делу, указывающего на утрату налоговым органом возможности взыскания налогов, пеней, штрафов, в том числе и в мотивировочной части судебного акта.

На данном примере мы видим, как последовательно менялась позиция суда. Изначально коллизионный интерес налогоплательщика в конечном итоге приобрел статус законного. Произошло это не в последнюю очередь из-за того, что новое видение ситуации более справедливое, чем прежнее.

\section{Генезис интереса налогоплательщика в позициях фискальных органов}

Изменение правовой позиции характерно не только для судов, но и для иных органов: Минфина России, ФНС России.

В силу подп. 5 п. 2 ст. 265 НК РФ при документальном подтверждении уполномоченным органом государственной власти факта отсутствия виновных лиц организация вправе признать во внереализационных расходах соответствующий убыток.

При этом НК РФ не содержит указания на то, какими именно документами может подтверждаться отсутствие виновных лиц. Это может быть как постановление о приостановлении следственных действий, так и постановление о прекращении уголовного дела, равно как и любой иной документ.

Однако в 2006 г. Минфин России категорично указал, что учет спорных недостач допустим только при условии вынесения следо- 
вателем постановления о прекращении уголовного дела [10]. В этом случае налогоплательщику пришлось бы ожидать неопределенно долгое время прекращения уголовного дела. Например, допустимый уголовно-процессуальным законодательством срок производства по уголовному делу по ч. 3 ст. 159 Уголовного кодекса РФ - 10 лет. После истечения 10 лет следователь вынесет постановление о прекращении уголовного дела.

Вместе с тем налогоплательщик не должен ставиться в положение, зависимое от эффективности действий соответствующих должностных лиц настолько, насколько это бы являлось непреодолимым препятствием для отражения им в налоговом учете полученных убытков от хищения, с учетом разумной продолжительности уголовного процесса и доступности к правосудию.

Обратное означало бы возложение на потерпевшего, выступающего в налоговом регулировании налогообязанным лицом - налогоплательщиком, неопределенных по срокам чрезмерных ограничений, в том числе (ограничение) права по списанию данной задолженности в расходы, уменьшающие налогооблагаемую прибыль, объективно существующим, лишение которого противоречит нормам налогового законодательства.

Если за все время расследования потерпевший по уголовному делу не получил искомого правосудия, то очевидно, что практика уголовного преследования не безупречна, а перспектива возмещения ему вреда приобретает туманные очертания настолько, что у потерпевшего объективно уменьшается (фактически утрачивается) уверенность в правовом эффекте от расследования в силу неуловимости виновного лица.

Соответственно, налогоплательщик в ситуации затянувшегося уголовного производства в соответствии с требованиями справедливости и разумности должен располагать возможностью списания во внереализационные расходы убытки от хищений, виновники которых не установлены, с моментом вынесения должностным лицом постановления о приостановлении следственных действий как одним из ранних по времени актов, документально подтверждающих факт отсутствия виновных лиц.
Данный подход отражает законный интерес налогоплательщика в более справедливом исчислении налоговой базы; скорейшей допустимости учета этих расходов и, как следствие, уменьшении налогового обязательства налогоплательщика.

В 2012 г. позиция Минфина России изменилась: в качестве соответствующего документального подтверждения стало допускаться и постановление о приостановлении предварительного следствия [9]. Справедливости ради отметим, что на изменение данной позиции повлияла соответствующая судебная практика. Суды изначально рассматривали постановление о приостановлении предварительного следствия допустимым документом для целей ст. 265 НК РФ. Тем не менее это не стало обстоятельством, исключающим налоговые споры.

\section{Выводы}

Обобщая вышеизложенное, можно подытожить: синтез права и интересов дает налогоплательщику надежду на осуществление их в будущем. Опыт предыдущих лет показывает, что идея реализации коллизионного интереса может быть сохранена и при текущих неблагоприятных для этого условиях. Необходима борьба за свой законный интерес. Основываясь на праве, коллизионные интересы претендуют на роль проводников правотворческих и правоприменительных инициатив. И даже если первая попытка реализации не привела к успеху, возврат к этой истории в дальнейшем неизбежен.

\section{СПИСОК ЛИТЕРАТУРЫ}

1. Амирбеков, К. И. Трансформация взглядов на понимание законности как правовой категории / К. И. Амирбеков // Российская юстиция. - 2016. № 4. - С. 2-5.

2. Аристотель. Политика / Аристотель ; [пер. с древнегреч. С. А. Жебелева]. - М. : АСТ, 2016. -384 c.

3. Годме, П.-М. Финансовое право / П.-М. Годме. -М. : Прогресс, 1978. -429 с.

4. Жилин, Г. А. Соотношение права и закона / Г. А. Жилин // Российская юстиция. - 2000. - №4. C. $8-10$. 
5. Ларин, А. М. Всегда ли прав суд, даже если он Конституционный? / А. М. Ларин // Российская юстиция. - 1997. - № 4. - С. 53-54.

6. Налоговый кодекс Российской Федерации (часть первая) от 31.07.1998 № 146-Ф3 // Собрание законодательства РФ. - 03.08.1998. - № 31. - Ст. 3824.

7. Ожегов, С. И. Толковый словарь русского языка : 80000 слов и фразеологических выражений / С. И. Ожегов, Н. Ю. Шведова. - М., 2006. - 944 с.

8. Определение Конституционного Суда РФ от 26.05.2016 № 1150-О «Об отказе в принятии к рассмотрению жалобы гражданина Кузнецова Сергея Тимофеевича на нарушение его конституционных прав подпунктом 4 пункта 1 статьи 59 Налогового кодекса Российской Федерации». - Электрон. дан. Доступ из СПС КонсультантПлюс.

9. Письмо Минфина России от 06.12.2012 № 03-03-06/1/630 // Нормативные акты для бухгалтера. -2013 . - № 4 .

10. Письмо Минфина России от 20.01.2006 № 03-03-04/1/52. - Электрон. дан. - Доступ из СПС КонсультантПлюс.

11. Постановление Пленума ВАС РФ от 30.07.2013 № 57 «О некоторых вопросах, возникающих при применении арбитражными судами части первой Налогового кодекса Российской Федерации». - Электрон. дан. - Доступ из СПС КонсультантПлюс.

12. Постановление Президиума ВАС РФ от 01.09.2009 № 4381/09 по делу № А27-8596/2008-2 // Вестник ВАС РФ. - 2009. - № 11.

13. Постановление Президиума ВАС РФ от 11.05.2005 № 16507/04 по делу № А55-4606/04-6 // Вестник ВАС РФ. - 2005. - № 8 .

14. Постановление ФАС УО от 10.04.2013 № Ф09-2590/13 по делу № А60-35256/2012. - Электрон. дан. - Доступ из СПС КонсультантПлюс.

15. Постановление ФАС ПО от 02.08.2007 по делу № А57-593/07. - Электрон. дан. - Доступ из СПС КонсультантПлюс.

\section{REFERENCES}

1. Amirbekov K.I. Transformatsiya vzglyadov na ponimanie zakonnosti kak pravovoy kategorii [Transformation of Views on the Understanding of Legality as a Legal Category] Rossiyskaya yustitsiya, 2016, no. 4, pp. 2-5.

2. Aristotel. Politika [Policy]. Moscow, AST Publ., 2016.384 p.

3. Godme P.-M. Finansovoe pravo [Financial law]. Moscow, Progress Publ., 1978. 429 p.

4. Zhilin G.A. Sootnoshenie prava i zakona [Correlation of Law and Statute]. Rossiyskaya yustitsiya, 2000, no. 4, pp. 8-10.
5. Larin A.M. Vsegda li prav sud, dazhe esli on Konstitutsionnyy? [Is the Court Always Right, Even if it is Constitutional?]. Rossiyskaya yustitsiya, 1997, no. 4, pp. 53-54.

6. Nalogovyy kodeks Rossiyskoy Federatsii (chast pervaya) ot 31.07.1998 № 146-FZ [Tax code of the Russian Federation (part one) Dated 31 July 1998 no. 146-FZ]. Sobranie zakonodatelstva RF [Collected Legislation of the Russian Federation], 1998, Aug. 03, no. 31 , art. 3824 .

7. Ozhegov S.I., Shvedova N.Yu. Tolkovyy slovar russkogo yazyka: 80000 slov $i$ frazeologicheskikh vyrazheniy [Explanatory Dictionary of Russian Language: 80000 Words and Phraseological Expressions]. Moscow, LLC “A TEMP” Publ., 2006. 944 p.

8. Opredelenie Konstitutsyonnogo Suda RF ot 26.05.2016 № 1150-O “Ob otkaze v prinyatii $k$ rassmotreniyu zhaloby grazhdanina Kuznetsova Sergeya Timofeevicha na narushenie ego konstitutsyonnykh prav podpunktom 4 punkta 1 statyi 59 Nalogovogo kodeksa Rossiyskoy Federatsii" [Determination of the Constitutional Court of the Russian Federation "About Refusal in Acceptance to Consideration of the Complaint of the Citizen Kuznetsov Sergey Timofeyevich on Violation of his Constitutional Rights by the Subparagraph 4 of Point 1 of Article 59 of the Tax Code of the Russian Federation" of May 26, 2016 No. 1150-O]. Access from Reference Legal System "KonsultantPlus".

9. Pismo Minfina Rossii ot 06.12.2012 № 03-03$06 / 1 / 630$ [Letter the Ministry of Finance of the Russian Federation of December 06, 2012 No. 03-03-06/1/630] Normativnye akty dlya bukhgaltera, 2013, no. 4.

10. Pismo Minfina Rossii ot 20.01.2006 № 03-03$04 / 1 / 52$ [Letter the Ministry of Finance of the Russian Federation of January 20, 2006 No. 03-03-04/1/52] Access from Reference Legal System "KonsultantPlus".

11. Postanovlenie Plenuma VAS RF ot 30.07.2013 № 57 «O nekotorykh voprosakh, voznikayushchikh pri primenenii arbitrazhnymi sudami chasti pervoy Nalogovogo kodeksa Rossiyskoy Federatsii» [Decision of the Plenum of the Supreme Arbitration Court "On Some Issues Arising in the Application of Arbitration Courts of the First Part of the Tax Code of the Russian Federation" of July 30, 2013 No. 57]. Access from Reference Legal System "KonsultantPlus".

12. Postanovlenie Prezidiuma VAS RF ot 01.09.2009 № 4381/09 po delu № A27-8596/2008-2 [Decision of the Presidium of the Supreme Arbitration Court of the Russian Federation of September 01, 2009 no. 4381/09 in Case No. A27-8596/2008-2]. Vestnik VAS $R F, 2009$, no. 11 .

13. Postanovlenie Prezidiuma VAS RF ot 11.05.2005 № 16507/04 po delu № A55-4606/04-6 [Decision of the 
С.А. Ядрихинский. Борьба за право, или Коллизионные аспекты законных интересов налогоплательщика

Presidium of the Supreme Arbitration Court of the Russian Federation of May 05, 2005 No. 16507/04 in case no. A55-4606/04-6]. Vestnik VAS RF, 2005, no. 8.

14. Postanovlenie FAS UO ot 10.04.2013 № F09-2590/13 po delu № A60-35256/2012 [Decision of the Federal Arbitration Court of Urals District of April 10, 2013 no. F09-2590/13 in Case No. A60-
35256/2012]. Access from Reference Legal System "KonsultantPlus".

15. Postanovlenie FAS PO ot 02.08 .2007 po delu № A 57-593/07 [Decision of the Federal Arbitration Court of Povolzhsky District of August 02, 2007 No. A57-593/07]. Access from Reference Legal System "KonsultantPlus".

\section{Information about the Author}

Sergei A. Yadrikhinsky, Candidate of Sciences (Jurisprudence), Associate Professor, Department of Administrative and Financial Law, North-Western Institute (Branch) of Kutafin Moscow State Law University (MSLA), Mira St., 32, 160001 Vologda, Russian Federation, Syadr@yandex.ru, https://orcid.org/ 0000-0002-5088-6095

\section{Информация об авторе}

Сергей Александрович Ядрихинский, кандидат юридических наук, доцент кафедры административного и финансового права, Северо-Западный институт (филиал) Университета им. О.Е. Кутафина (МГЮА), ул. Мира, 32, 160001 г. Вологда, Российская Федерация, Syadr@yandex.ru, https://orcid.org/0000-0002-5088-6095 